\title{
John Dewey: A Look at His Contributions to Curriculum
}

Latasha Holt, Ph.D.

University of Louisiana at Lafayette, United States of America

\begin{abstract}
This article provides a thorough analysis of John Dewey and his theory experimentalism. John Dewey was a leader in education and philosophy of his time. Still today his ideologies have a place in educational curriculums across the globe. John Dewey believed that students learn from human experiences. Furthermore, Dewey believed that student experiences shape the future decisions that a learner engages in. Although Dewey's work faced scrutiny, Dewey's thoughts are still relevant in education reform today. This article resurfaces the need for whole child research considerations and inclusive learner experiences like Dewey's work many years ago when making educational decision and building curriculum that meet the needs of individuals to promote a positive global change.
\end{abstract}

Keywords: experimentalism; curriculum; John Dewey; educational reform; global impact.

\section{Introduction}

John Dewey was one of the major leading educational scholars of all time. His background includes his job as an educator, a psychologist, philosopher, and political activist. He graduated from the University of Vermont in 1879 and received his Ph.D. from John Hopkins University in 1884. He taught at the University of Michigan and the University of Minnesota. He also taught at the University of Chicago where he served as department chair. He retired from Columbia University in 1929. During these years of service, he made a lasting influence on education for so many. John Dewey's impact should be remembered, revisited, and considered when looking to solve the global-wide challenges we face in the present day. This article focuses on the connection of research from his philosophy related to experimentalism and the relevance in today's world. Furthermore, this article is a synthesis of research that is a call to action for leaders across the globe to consider when visiting the topic of curriculum design that will be an integral part of the behaviors we see in societies.

\section{Analysis}

John Dewey had numerous contributions to education. Dewey boldly identified experimentalism, which centered on human experiences, as the method in which an individual could grow with personal knowledge. This idea Dewey not only hypothesized but became the devotion he would spend his life proving. Publishing 
over one-thousand works covering a plethora of information that is still valued today, John Dewey's focus remained that an individual learns from life experiences and thus needs life experiences to enhance understandings. These human life experiences are the contribution to how an individual makes informed decisions with future situations. Many years later, this idea still remains true.

John Dewey's ideas that he expressed relating to experimentalism provided leadership norms for American thinkers and other activists from the Progressive era through the Great Depression (Waks, 1998). Being born, and living, during a time of great change in America, John Dewey's ideas were not always accepted. The United States was on the brink of the Civil War, and Dewey's father would serve in that war. John Dewey's life events shaped who he would be and undoubtedly impacted his views as he was beginning his teaching career.

Continuing his years in a very active role in education, Dewey's philosophical views evolved. John Dewey worked with several different countries, besides the United States, which included Mexico, Japan, and South Africa. These countries and others were important to shape ideas and confirm what he knew to be the truth. John Dewey's writings were translated in many languages shared in China, Russia, and Turkey. Overall, his knowledge grew from both his local and global experiences that grounded his ideas and motivated his expression.

\section{Vocalization of his beliefs}

Right away John Dewey was vocal about his beliefs. In all avenues of expression, he was a part of his call to action was expressed. He commented on the industrial revolution, and the impact that it was having on the communities in American and beyond. He knew that classrooms were not prepared to embrace a new social structure and economic needs that came with such a revolution. John Dewey avidly believed in the role of democracy and the importance of creating classrooms that reflect democratic values so that children would learn to function in the greater democratic society they were expected to be a part of.

Dewey's philosophies further emerged as he began to study the works of Colonel Francis Park. To research his collected beliefs, Dewey began his own school in 1896 referred to as the Dewey Laboratory School. The school was officially named the University Elementary School which was under his supervision. He used the school as an experimental laboratory to promote the study of teaching, learning, and administration, not as a model for other educators and schools to imitate (simpson \& Stack, 2010).

As John Dewey modeled with the lab schools, it remains valuable that we consider the wealth of information that can be gained when role-model school systems hold the 
possibility of increased strength by utilizing the lab school model to ultimately promote teaching and learning. When individuals are allowed to flourish in an environment like the lab school that affords the experimentalism approach to be used, individual thinking and creating will be enhanced. Additionally, learning more about lab schools and the benefits for learners can be made possible when these practices are initiated, documented, and shared with professional learning communities for the good of mankind. In these active learning situations, the democratic foundations should be implied to allow connections for individuals in both the teaching and learning roles.

Based on the aforementioned, an effective teacher should possess qualities that promote independence in a democratic society while also remaining knowledgeable about the content area he or she should be an expert in. Additionally, an effective teacher should be open-minded to changes and model good citizenship. He or she should also possess qualities of a good communicator that can collaborate with other professionals to reach the highest of expectations that are possible for students. In addition, the effective teacher must be prepared to think globally about how each student can compete with others for jobs in the future and help to foster growth and use experiential learning to reach personal goals.

\section{Recreating experimentalism}

The impact we connect from John Dewey's legacy is that learning is a process of experiential growth, always in the state of becoming and if properly managed, improving, but never achieving completeness or finality. However, such a view of experience does not emerge idiosyncratically. Each individual comes with unique experiences, or lack of experiences, that make this process very personal. For those in educational roles, it is important to use a personal approach to with the learning process. Some methods of thinking or a process of intelligence has to be used to help regulate it (Hlebowitsh, 2006). John Dewey understood that human mind is ever changing, and educators have a critical role in that change. This idea is still true with teaching and learning in the present. It is vital that we understand the role that school systems and others involved in the educational process have on others.

Today curriculums are designed and implemented in a variety of specific areas. There are commercially based companies that produce these programs that must be designed and implemented with caution. Possibly, it should be made known that there is not one way for information to be taught much like curriculums thrive upon. More experimentalism-based learning would be better suited. Without proper implementation of well-established, departmentalized curriculum that is carefully balanced with the learner in mind societies suffer. As these individual learners transition into adults longing to survive in the ever-changing world that surrounds them, unfavorable outcomes will arise. We must remember that individuals need 
to have connections and opportunities for experimental learning set inside of a democratic culture.

Furthermore, to better understand this idea of experimentalism, it is important to remember the basic principle of experimentalism has a broader philosophical connection to what originated as pragmatism. The pragmatist's prejudice is to affect the here and now, to look at life as a matter of present significance, and not as a matter that has some ultimate judgment at the pearly gates of heaven or some other transcendental place (Hlebowitsh, 2006). This root was the start of a more specific ideology Dewey explained through experimentalism throughout his life's work. In other words, in order for deeper thinking to emerge, the educator and learner must be present in small teaching moments that connect to the individual's passions (Lang, 2016).

Dewey believed that as an "individual passes from one situation to another, his world, his environment, expands or contracts. He does not find himself living in another world but in a different part or aspect of one and the same world. What he has learned in the way of knowledge and skill in one situation becomes an instrument of understanding and dealing effectively with the situations which follow. The process goes on as long as life and learning continues. Today we can hypothesize that students must be given opportunities self-discover ways to navigate situations that arise. In other words, "the course of experience is disorderly, since the individual factor that enters into making an experience is split" (Dewey, 1989, p.25). Hlebowitsh reiterated this with the quote "the cliché that knowledge is power has very definite meaning among experimentalists. The power is not in the contribution that knowledge makes to one's mind, but in its contribution to one's behavior" (2006, p.75).

\title{
Whole child curriculum is needed
}

John Dewey's book The Child and the Curriculum contains the heart of his philosophies. Dewey states:

\begin{abstract}
"abandon the notion of subject-matter as something fixed and ready-made in itself, outside the child's experience; cease thinking of the child's experience as also something hard and fast; see it as something fluent, embryonic, vital; and we realize that the child and the curriculum are simply two units which define a single process. It is continuous reconstruction, moving from the child's present experience out into that represented by the organized bodies of truth that we call studies" (Dewey, 1902, p.11).
\end{abstract}

His ideas transitioned into his theory that would become foundational in education. Experimentalism in education has its emphasis on naturalism, behaviorism, and individualism, slights moral values, since values are derived from historical traditions and communal living and not from the individual (Miller, 1958). This can be explained more by looking at the works of Maslow. As educators we know that a child must feel 
safe, secure, and loved to reach his or her full potential. Maslow's Hierarchy of Needs defines these needs in the following order of importance: physiological needs, safety needs, social needs, self-esteem, and last is self-actualization. One must satisfy lower level basic needs before progressing on to meet higher level growth needs. Once these needs have been reasonably satisfied, one may be able to reach the highestlevel called self-actualization (McLeod, 2007).

These collective ideas are important today as we are identifying a variety of behaviors that are identified as challenging or disruptive in the classroom. The focus on individual behavior is especially important, because as a philosophy of democracy, experimentalism ultimately judges the effects of schooling against some standard of betterment or progress in the life experience. All needs, including the social needs of a student, must be met in order to for the child to be successful. Educators need an understanding of the different learning styles that best fit the students. These learning styles may be hands-on, verbal, visual, auditory, or a combination of these. This may also vary from subject to subject with the individual child.

More recent research expounds that the whole child curriculum model contains five main focuses that serve as the foundation for all other curriculum domains. These five focuses include individual health, safety, engagement, support from others, and challenging activities (Slade \& Griffith, 2013). The correlation of whole child emphasis along with the work of John Dewey explained in his lectures and writings is important to note for value then and now. It is also important to use the information in the research highlighted in this article to consider a specific look into the recent mental health crisis effecting so many individuals.

Waks furthered these ideas in 1998 with his article explaining that people [students] as actors in society need philosophies as relating to life, or as general schemes of living and measures of can value (p.4). Though each person needs to face life's problems anew, his or her ideas are absorbed, in large measure, from philosophical currents inhering in contemporary culture. These public philosophies assign to each interest setting forth the "distinctive role of each in a way that will harmonize its demand with that of other ends" (Boydston, 1969, p.301). This is where the structure of the learning community in the school and classroom instruction comes into play.

\section{Implications of Dewey's Ideas}

Despite the strengths of Dewey's theory, historically the idea of experimentalism has taken on some strong criticism. Our "postmodern" culture is in some ways also unfavorable to Dewey's brand of philosophy, particularly to the central role it assigns to science. As a consequence, those taking up the Deweyan heritage have in different ways tried to tease it apart from its commitment to scientific method. Some downplay 
scientific method in his philosophy, denying that he meant science in the strong sense suggested by, for example, physics or physiology (Waks, 1998).

Others have said the science of his ideas are strong, but that science is just one idea among many others and that a revitalized pragmatist philosophy should abandon proscientism in favor of a conception of philosophy no closer to science than others feel is close to art. Dewey often used science as a synonym for reason, intelligence and reflective thought, a practice that did not manifest, as some have charged, an unduly narrow notion of the latter terms, but rather a willingness to offer relatively relaxed entrance requirements to the house of science (Waks, 1998). This remains a great debate still today.

We can see experimentalism in current reforms in America and beyond. The No Child Left Behind Reform by the Bush Administration had many components that were founded on experientialism. One specific example from Rushton \& Rushton (2008) looked at the how can the needs of the No Child Left Behind reform can be addressed through a study grappled with brain research and what has to scientifically happen for learning to occur. This was strikingly similar to Dewey's ideas in experimentalism. Every Student Succeeds Act followed suit with many of the same ideas that can be assimilated, yet still struggling to make a significant impact on educational outcomes.

Overall, the research has showed that aligning best practices to the brain's natural chemistry is needed for success. This becomes more complicated when viewed from the perspective of the high stakes testing arena that we see as mandatory in the No Child Left Behind reform (and others similar to it) and the goals within. John Dewey (1964) objected to the traditional method of learning by memory under what teachers believed to be 'correct' and 'conventional' approaches to both teaching and assessing learning. Dewey and many modern-day constructivists believe education should entice the natural interest of students via authentic real-life experiences that are relevant to the child's life experiences (Rushton \& Rushton, 2008). Therefore, abandoning Dewey's ideas to implement high-stakes testing desired to assess students success in a given curriculum can be seen as counterproductive.

Thinking about the theory of experimentalism and the expectations that we are putting on today's students is clearly worth our time in all educational discussions and decisions. Students need more support from the school system to work out issues with their behaviors that are affecting them academically. Childhood is a hybrid of both culture and nature. It demands multi- and interdisciplinary analysis and the creation of a theoretical language that can merge these different concerns (James \& Prout, 2015). 


\section{Transforming education across the globe}

As mentioned previously, the importance of John Dewey's theories can be found today in whole child research needed. Connecting, Dewey's writings during his lifetime reaffirm the fact that he believed not only that education, like society, was constantly changing but also that both needed to be reflectively guided (Simpson \& Stack, 2010). Hlebowitsh (2006) elaborated on Dewey's ideas of experimentalism stating that the whole child must be educated, not just his or her mind. From the standpoint of the child, the great waste in the school comes from his inability to utilize the experiences he gets outside the school in any complete and free way within the school itself; while on the other hand; he is unable to apply in daily life what he is learning in school (Dewey, 1967).

As the student sees, feels and experiences modeled demonstrations of a lesson, artifacts, or some action) the brain maps out the experience in a unique manner (Hlebowitsh, 2006). The purpose of education should be aligned with the goals of the learner within the community. Noddings (2005) reminded us that all students deserve rich educational experiences - experiences that will enable them to become active citizens in a democratic society. This includes curing social ills that need to be addressed including poverty and crime as well as health concerns. While the purpose of education can be debated, it is critical that we understand that as educators we play a valuable role in the end results. This was stated in Dewey's theory as well as with more modern research. It is worth our consideration. Revisiting these ideas is needed for globalized change to begin.

\section{Questions for Further Research}

As we analyze this as a whole, there are some questions that can be used for further research.

1. After analyzing experimentalism, how can we include components from John Dewey's hands-on approach to daily classroom curriculum to meet social needs in the classroom in 2020 ?

2. How can we combine information about how the human brain interacts with the environment along with John Dewey's theory to develop ideas that can be used to meet the needs of students with standardized testing?

3. How can we use the basis of experimental learning to better support global challenges that we face? 


\section{Conclusion}

In conclusion, it is clear that John Dewey's idea of experimentalism is one that is still remains relevant to education today. Although there are many critics that are arguable, a need has been established for Dewey's theory implemented in today's educational system. Looking at experimentalism through a new current lens can help better understand the relationship with the experiences, or lack of experiences, our students are interacting with and how it is affecting the individuals in the classroom and into society. Educators and researchers can use the knowledge gained to advocate for needed change that can better benefit the global challenges we are facing in today's times. Educators should be encouraged and reminded to review curriculum decisions with experimentalism being considered. John Dewey's work is still applicable generations later.

\section{Bibliography}

1. Berkson, I. B. (1958). The ideal and the Community.

2. Boydston, J. A. (1969). The Collected Works of John Dewey, 1882-1953 (37 Volumes).

3. Dewey, J. (1938). Experience and education. Simon and Schuster.

4. Dewey, J. (1902). The child and the curriculum. (No.5). University of Chicago Press.

5. Dewey, J. (1967). The School and the Society: Rev. Ed. University of Chicago Press.

6. Dewey, J. (1989). The Later Works of John Dewey, 1949-1952: 1949-1952, Essays, Typescripts, and Knowing and the Known (Vol. 16). SIU Press.

7. Hlebowitsh, P. S. (2006). John Dewey and the idea of experimentalism. Education and Culture, 22(1), 73-76.

8. James, A., \& Prout, A. (Eds.). (2015). Constructing and reconstructing childhood: Contemporary issues in the sociological study of childhood. Routledge.

9. Lang, J. M. (2016). Small teaching: Everyday lessons from the science of learning. John Wiley \& Sons.

10. Marsonet, M. (2013). Pragmatism and Science. Academicus International Scientific Journal, 4(08), 101-109.

11. McLeod, S. (2007). Maslow's hierarchy of needs. Simply Psychology, 1.

12. Miller, H. (1958). A Scholarly Critique of Dewey and Experimentalism in Education. The Journal of Educational Sociology, 133-140. 
13. Noddings, N. (2005). What does it mean to educate the whole child? Educational leadership, 63(1), 8.

14. Rushton, S., \& Juola-Rushton, A. (2008). Classroom learning environment, brain research and the no child left behind initiative: 6 years later. Early Childhood Education Journal, 36(1), 87-92.

15. Simpson, D. J., \& Stack, S. F. (Eds.). (2010). Teachers, leaders, and schools: Essays by John Dewey. SIU Press.

16. Slade, S., \& Griffith, D. (2013). A whole child approach to student success. KEDI Journal of Educational Policy, 10(3).

17. Waks, L. J. (1998). Experimentalism and the flow of experience. Educational Theory, 48(1), 1-19. 